\title{
Formulation and Evaluation of Ethosomes for Transdermal Delivery of Lamivudine
}

Received: February 22, 2007; Final Revision Received: July 13, 2007; Accepted: July 18, 2007; Published: December 21, 2007 Subheet Jain, ${ }^{1}$ Ashok K. Tiwary, ${ }^{1}$ Bharti Sapra, ${ }^{1}$ and Narendra K. Jain ${ }^{2}$

${ }^{1}$ Department of Pharmaceutical Sciences and Drug Research, Punjabi University, Patiala, India

${ }^{2}$ Pharmaceutics Research Laboratory, Department of Pharmaceutical Sciences, Dr. H. S. Gour University, Sagar [Madhya Pradesh] 470003 India

\section{ABSTRACT}

The purpose of the present research was to investigate the mechanism for improved intercellular and intracellular drug delivery from ethosomes using visualization techniques and cell line study. Ethosomal formulations were prepared using lamivudine as model drug and characterized in vitro, ex vivo and in vivo. Transmission electron microscopy, scanning electron microscopy, and fluorescence microscopy were employed to determine the effect of ethosome on ultrastructure of skin. Cytotoxicity and cellular uptake of ethosome were determined using T-lymphoid cell line (MT-2). The optimized ethosomal formulation showed 25 times higher transdermal flux $\left(68.4 \pm 3.5 \mu \mathrm{g} / \mathrm{cm}^{2} / \mathrm{h}\right)$ across the rat skin as compared with that of lamivudine solution $\left(2.8 \pm 0.2 \mu \mathrm{g} / \mathrm{cm}^{2} / \mathrm{h}\right)$. Microscopic studies revealed that ethosomes influenced the ultrastructure of stratum corneum. Distinct regions with lamellar stacks derived from vesicles were observed in intercellular region of deeper skin layers. Results of cellular uptake study showed significantly higher intracellular uptake of ethosomes $(85.7 \% \pm 4.5 \%)$ as compared with drug solution $(24.9 \% \pm 1.9 \%)$. The results of the characterization studies indicate that lipid perturbation along with elasticity of ethosomes vesicles seems to be the main contributor for improved skin permeation.

KEYWORDS: Ethosomes, skin, transmission electron microscopy, scanning electron microscopy, fluorescence microscopy, cell line study.

\section{INTRODUCTION}

Human immunodeficiency virus (HIV) is a retrovirus that causes irreversible destruction of the immune system. During the last decade, even though attempts were being made to eradicate HIV but it was found that eradication of

Corresponding Author: Subheet Jain, Department of Pharmaceutical Sciences and Drug Research, Punjabi University, Patiala, Patiala [Punjab] 147002 India. Tel: +91-175-3046304; Fax: +91-175-2283073; E-mail: subheetjain@rediffmail.com
HIV is highly unlikely, and effective antiretroviral therapy is required on a long-term basis to maintain viral suppression and reduce disease progression. Lamivudine is a commonly used hydrophilic antiviral drug for treatment of acquired immunodeficiency syndrome (AIDS and hepatitis. Lamivudine has a short biological half-life (4-6 hour) and requires frequent administration for a prolonged period of time (lifelong in AIDS and for one year in hepatitis patients). ${ }^{1,2}$ Transdermal route is, therefore, a better alternative to achieve constant plasma levels for prolonged periods of time, which additionally could be advantageous because of less frequent dosing regimens.

The use of lipid vesicles as drug delivery systems for skin treatment has attracted increasing attention in recent years. However, it is generally accepted that conventional liposomes are of little value for this purpose. Liposomes remain confined to the upper layer of stratum corneum (SC) and, hence, are suitable for topical drug delivery. ${ }^{3}$ Only specially designed vesicles were shown to deliver drugs across the skin layers. ${ }^{4,5}$

Touitou ${ }^{6}$ discovered lipid vesicular systems ethosomes embodying ethanol in relatively high concentration. Ethosomes contain phospholipids, alcohol (ethanol and isopropyl alcohol) in relatively high concentration and water. Unlike classical liposomes, ethosomes were shown to permeate through the stratum corneum barrier and were reported to possess significantly higher transdermal flux in comparison to liposomes. ${ }^{5-9}$ Although, the exact mechanism for better permeation into deeper skin layers from ethosomes is still not clear. The synergistic effects of combination of phospholipids and high concentration of ethanol in vesicular formulations have been suggested to be responsible for deeper distribution and penetration in the skin lipid bilyers. ${ }^{8}$

In the previous study, the in vitro skin permeation of ethosomal zidovudine formulation was studied and was found to be 24-fold higher as compared with aqueous drug solution. ${ }^{9}$ The present study was aimed at investigating the possible mechanism of intracellular and intercellular delivery of ethosomes containing lamivudine as model drug using scanning electron microscopy (SEM), transmission electron microscopy (TEM), and fluorescence microscopy techniques and cell line studies. Lamivudine encapsulation in ethosomes 
could increase its skin permeation and intracellular uptake. This would enhance its antiviral efficiency and lead to better patient compliance.

\section{MATerials AND Methods}

\section{Materials}

Lamivudine was received as a gift sample from Cipla Ltd (Mumbai, India). High purity soyaphosphatidyl choline $(99 \%, P C)$ was purchased from Sigma Chemicals (St Louis, $\mathrm{MO}$ ), and it was used without further purification. Cholesterol, Sephadex-G-50, Triton-X 100, osmium-tetraoxide, Rhodamine-123, 3-(4,5-dimethyl-2-thiazolyl)-2,5-diphenyl2H-tetrazolium bromide (MTT), and ruthenium-tetraoxide were also purchased from Sigma Chemicals. Roswell Park Memorial Institute (RPMI) 1640 and fetal calf serum were purchased from Himedia Ltd (Mumbai, India). All other reagents used in the study were of analytical grade.

\section{Preparation of Formulations}

Ethosomal formulations were prepared according to the method reported by Touitou. ${ }^{7}$ Phospholipid and drug or fluorescent probe (Rhodamine 123) were dissolved in ethanol. This mixture was heated to $30^{\circ} \mathrm{C} \pm 1^{\circ} \mathrm{C}$ in a water bath. Double-distilled water heated to $30^{\circ} \mathrm{C} \pm 1{ }^{\circ} \mathrm{C}$ was added slowly as a fine stream to lipid mixture with constant stirring (mechanical stirrer; Remi Equipment; Mumbai, India) at $700 \mathrm{rpm}$ in a closed vessel. Mixing was continued for an additional 5 minutes, while maintaining the system at $30^{\circ} \mathrm{C} \pm 1{ }^{\circ} \mathrm{C}$. The resulting vesicle suspension was homogenized by passing through polycarbonate membrane of 400,200 , or $100 \mathrm{~nm}$ according to initial size of formulation using hand extruder (Millipore, Billerica, MA) for 3 cycles. The classical liposomal formulation that was used as a control in the present study was prepared by well-known cast film method as described by Bangham et al. ${ }^{10}$

\section{Characterization of Ethosomal Formulations}

Vesicle size and zeta potential were determined by dynamic light scattering method (DLS), using a computerized inspection system (Malvern Zetamaster, ZEM 5002, Malvern, UK). For morphological characterization, TEM studies using phosphotungstic acid as negative stain were performed (Philips, 400T, TEM, New Brunswick, Canada).

The drug entrapment efficiency was determined by dialysis method. Cellulose acetate membrane (Himedia, Mumbai, India, molecular weight cut off 14,000) was kept in saline solution for 1 hour before dialysis to ensure complete wetting of the membrane. One milliliter of the drug-loaded vesicles was placed in the dialysis bag, which was then transferred into $500 \mathrm{~mL}$ of phosphate buffer saline (PBS) (pH 6.5).
The receiver medium was stirred with a magnetic stirrer. Sample was withdrawn after 0.5-, 1.0-, 1.5-, 2.0-, 2.5-, 3.0-, 3.5-, and 4.0-hour time intervals and replaced with equal volumes of PBS. After 4 hours when free drug was separated, vesicles were lysed using Triton-X $100(0.1 \% \mathrm{vol} / \mathrm{vol})$ and analyzed for drug content. ${ }^{11}$ This method was able to separate all the free drug as evidenced by more than $90 \%$ drug permeation in 1 hour across dialysis membrane in control experiments using drug solution. Integrity of dialysis membrane $\left(2.54 \mathrm{~cm}^{2}\right)$ after incubating with $1 \mathrm{~mL}$ of $50 \% \mathrm{vol} / \mathrm{vol}$ ethanolic solution for 2 days was determined by microscopic observation. No significant alteration in morphology was found.

\section{Elasticity Measurement}

\section{Extrusion Method}

The elasticity of ethosome vesicle membrane was determined by extrusion method as described earlier. ${ }^{12}$ The ethosomal formulations were extruded through filter membrane (pore diameter $50 \mathrm{~nm}$ ), using a stainless steel filter holder having $25-\mathrm{mm}$ diameter, by applying a pressure of 2.5 bar. The quantity of vesicle suspension, extruded in 5 minutes was measured. Vesicle shape (by TEM) and size (by DLS) were monitored before and after filtration. The elasticity of vesicle membrane was calculated by using the following formula:

$$
E=J *\left(r_{v} / r_{p}\right)^{2}
$$

where, $E$ is elasticity of vesicle membrane; $J$ is the amount of suspension extruded in 5 minutes; $r^{v}$ is vesicle size (after extrusion); and $r^{p}$ is pore size of the barrier

\section{Filter Membrane-Vesicle Interaction Study by Scanning Electron Microscopy}

Vesicle suspension $(0.2 \mathrm{~mL})$ was applied to filter membrane having a pore size of $50 \mathrm{~nm}$ and placed in diffusion cells. The upper side of the filter was exposed to the air, whereas the lower side was in contact with PBS (pH 6.5). The filters were removed after 1 hour and prepared for SEM studies by fixation at $4{ }^{\circ} \mathrm{C}$ in Karnovsky's fixative overnight followed by dehydration with graded ethanol solutions $(30 \%, 50 \%$, $70 \%, 90 \%, 95 \%$, and $100 \% \mathrm{vol} / \mathrm{vol}$ in water). Finally, filters were coated with gold and examined in SEM (Leica, Bensheim, Germany). ${ }^{13}$

\section{Skin Permeation Study}

Rats (Sprague-Dawley strain) 6 to 8 weeks old weighing 120 to $150 \mathrm{~g}$ were humanely killed by chloroform inhalation. The hair of test animals were carefully trimmed short $(<2 \mathrm{~mm})$ 
with a pair of scissors, and the abdominal skin was separated from the underlying connective tissue with a scalpel. The excised skin was placed on aluminum foil, and the dermal side of the skin was gently teased off for any adhering fat and/or subcutaneous tissue. ${ }^{13}$

The in vitro skin permeation of lamivudine from different formulations was studied using Franz glass diffusion cells. The effective permeation area of the diffusion cell and receptor cell volume was $1.0 \mathrm{~cm}^{2}$ and $10 \mathrm{~mL}$, respectively. The temperature was maintained at $32^{\circ} \mathrm{C} \pm 1{ }^{\circ} \mathrm{C}$. The receptor compartment contained PBS (10 mL of $\mathrm{pH} 6.5)$. Excised skin was mounted between the donor and the receptor compartment. Ethosomal formulation $(1.0 \mathrm{~mL})$ was applied to the epidermal surface of skin. Samples $(0.5 \mathrm{~mL})$ were withdrawn through the sampling port of the diffusion cell at 1-, 2-, 4-, 8-, 12-, 16-, 20-, and 24-hour time intervals and analyzed by high-performance liquid chromatography (HPLC) assay. An equal volume of fresh phosphate buffer maintained at $32^{\circ} \mathrm{C} \pm 1{ }^{\circ} \mathrm{C}$ was replaced into the receptor compartment after each sampling. All investigations were performed after approval by the Institutional Ethical Committee and in accordance with the disciplinary principles and guidelines of the Committee for the purpose of control and supervision of experiments on animals.

\section{Stability Study}

Stability of the vesicles was determined by storing the vesicles at $4^{\circ} \mathrm{C} \pm 0.5^{\circ} \mathrm{C}$. Vesicle size, zeta potential, and entrapment efficiency of the vesicles was measured after 180 days using the method described earlier.

\section{Vesicle-Skin Interaction Study by TEM and SEM}

Rats (Sprague Dawley strain) weighing (100-150 g) were divided into 4 groups, each consisting of 3 animals. First group served as control and received topical application of PBS. The second, third, and fourth groups received hydroethanolic solution ( $45 \%$ ethanol in water), optimized ethosomal formulation $\left(\mathrm{ETH}_{3}\right)$, and liposomal formulation, respectively. The treated areas of animals were protected by using nylon mesh, which was supported by plastic squares having small pores. The treated rats were caged individually and humanely killed after 6 hours of treatment. ${ }^{13}$ The skin was removed immediately and fixed at $4^{\circ} \mathrm{C}$ in Karnovsky's fixative overnight followed by $1 \%(\mathrm{wt} / \mathrm{vol})$ osmium-tetraoxide for 2 hours and finally in a solution containing rutheniumtetraoxide $0.2 \%(\mathrm{wt} / \mathrm{vol})$ and $\mathrm{K}_{3} \mathrm{Fe}(\mathrm{CN})_{6} \quad 0.25 \%(\mathrm{wt} / \mathrm{vol})$ for 1 hour. Following fixation, the samples were dehydrated in a range of ethanolic solutions $(70 \%, 90 \%, 95 \%$, and $100 \% \mathrm{vol} / \mathrm{vol}$ ) and embedded in Spurr's resin. Ultrathin sections were cut (Ultracut, Vienna, Austria), collected on formvar-coated grids and examined under transmission electron microscope.

For SEM analysis, the sections of skin after dehydration were mounted on stubs using an adhesive tape and were coated with gold palladium alloy using a fine coat ion sputter coater. The sections were examined under scanning electron microscope.

\section{Vesicle-Skin Interaction Study by Fluorescence Microscopy}

Fluorescence microscopy was carried according to the protocol used for TEM and SEM study. Ethosomes loaded with fluorescence marker Rhodamine 123 were prepared according to the method described earlier in preparation section. The fluorescent marker-loaded formulations were applied to dorsal portion of rats. After 6 hours of application, the rats were humanely killed; the skin was removed, cut into small pieces, and fixed using conventional method. Paraffin blocks were made, $5-\mu \mathrm{m}$ thick sections were cut using microtome (Erma optical works, Tokyo, Japan) and examined under a fluorescence microscope (Leica, DMRBE, Bensheim, Germany).

\section{Cytotoxicity Assay}

MT-2 cells (T-lymphoid cell lines) were propagated in Dulbecco's modified Eagle medium (HIMEDIA, Mumbai, India) containing $10 \%$ fetal calf serum, $100 \mathrm{U} / \mathrm{mL}$ penicillin, $100 \mathrm{mg} / \mathrm{mL}$ streptomycin, and $2 \mathrm{mmol} / \mathrm{L} \mathrm{L}$-glutamine at $37^{\circ} \mathrm{C}$ under a $5 \% \mathrm{CO}_{2}$ atmosphere.

Cytotoxicity of lamivudine ethosomal formulation was compared with marketed formulation (oral solution containing lamivudine $10 \mathrm{mg} / \mathrm{mL}$ ) and drug solution in PBS (pH 7.4) using MTT assay. MT2 cell suspension $100 \mu \mathrm{L}\left(0.01 \times 10^{6}\right) /$ well to the 96 well was seeded in flat-bottom tissue culture plate (Corning Inc, Corning, NY). The ethosomal formulation, marketed formulation, or drug solution in PBS was added in the 96-well flat-bottom tissue culture plate, mixed thoroughly, and incubated at $37^{\circ} \mathrm{C} \pm 0.5^{\circ} \mathrm{C}$ for 5 days in $\mathrm{CO}_{2}$ incubator (NuAire, Inc., Rochester, NY). The concentration range of lamivudine was 9.36 to $0.002 \mu \mathrm{mol} / \mathrm{mL}$. On the 5th post-infection day, $100 \mu \mathrm{L}$ MTT solution $(0.5 \% \mathrm{wt} / \mathrm{vol}$ in RPMI medium) was added to each well, and the plate was incubated at $37^{\circ} \mathrm{C} \pm 0.5^{\circ} \mathrm{C}$ for 4 hours. After 4 hours, the content of each cell was removed and the converted dye was solubilized in $150 \mu \mathrm{L}$ acidic isopropanol $(0.04 \mathrm{~N} \mathrm{HCl}$ in absolute isopropanol). Absorbance of converted dye was measured at wavelength of $540 \mathrm{~nm}$ with background subtraction at $690 \mathrm{~nm} .{ }^{14}$ Cytotoxicity was expressed as the cytotoxic dose $50\left(\mathrm{CD}_{50}\right)$ that induced a $50 \%$ reduction of absorbance at $540 \mathrm{~nm}$. 
AAPS PharmSciTech 2007; 8 (4) Article 111 (http://www.aapspharmscitech.org).

Table 1. Composition of Different Ethosomal Formulations

\begin{tabular}{lcccc}
\hline $\begin{array}{l}\text { Formulation } \\
\text { Code }\end{array}$ & $\begin{array}{c}\text { Phospholipid } \\
(\% \text { wt/wt })\end{array}$ & $\begin{array}{c}\text { Ethanol } \\
(\% \mathrm{wt} / \\
\text { wt })\end{array}$ & $\begin{array}{c}\text { Cholesterol } \\
(\% \mathrm{wt} / \mathrm{wt})\end{array}$ & $\begin{array}{c}\text { Drug } \\
(\% \mathrm{wt} / \\
\text { wt })\end{array}$ \\
\hline $\mathrm{ETH}^{\mathrm{a}}{ }_{1}$ & 2.0 & 15 & - & 0.4 \\
$\mathrm{ETH}_{2}$ & 2.0 & 30 & - & 0.4 \\
$\mathrm{ETH}_{3}$ & 2.0 & 45 & - & 0.4 \\
$\mathrm{ETH}_{4}$ & 2.0 & 60 & - & 0.4 \\
$\mathrm{ETH}_{3}$-Ch & 2.0 & 45 & 0.15 & 0.4 \\
$\mathrm{LP}^{\mathrm{b}}$ & 2.0 & - & 0.15 & 0.4 \\
\hline
\end{tabular}

$\mathrm{a}$ indicates ethosomal formulation; $\mathrm{b}$, liposomal formulation

\section{Drug Uptake Studies}

The uptake of lamivudine into MT- 2 cells $\left(1 \times 10^{6}\right.$ cells $\left./ \mathrm{mL}\right)$ was performed in 24-well plates (Corning Inc) in which $100 \mu \mathrm{L}$ RPMI medium was added. Cells were incubated with $100 \mu \mathrm{L}$ of the drug solution in PBS (pH 7.4), ethosomal formulation, or marketed formulation, each having lamivudine concentration of $0.58 \mu \mathrm{mol} / \mathrm{mL}$. The medium was removed at different time intervals $(0,20,40,60,120$, and 180 minutes), and cells were washed 4 times with Hank's balanced salt solution (HBSS) at $4^{\circ} \mathrm{C} \pm 0.5^{\circ} \mathrm{C}$. Cells were than resuspended and digested by incubation with $500 \mu \mathrm{L}$ $0.05 \%$ Triton $\mathrm{X}-100$ overnight at $4^{\circ} \mathrm{C}$. This mixture was filtered through $0.45-\mu \mathrm{m}$ filter, and drug uptake was determined by analyzing the drug content by HPLC assay. ${ }^{15}$

\section{HPLC Assay}

The amount of drug permeated in the receptor compartment during in vitro skin permeation experiments and in MT- 2 cell was determined by HPLC assay using methanol:distilledwater:acetonitrile $(70: 20: 10 \mathrm{vol} / \mathrm{vol})$ mixture as mobile phase delivered at $1 \mathrm{~mL} / \mathrm{min}$ by LC 10-AT vp pump (Shimadzu, Kyoto, Japan). A twenty-microliter injection was eluted in C18 column $(4.6 \times 150 \mathrm{~mm}$, Luna, 54, Shimadzu) at room temperature. The column eluent was monitored at $271 \mathrm{~nm}$ using SPD-M10A vp diode array UV detector. ${ }^{16}$ The coefficient of variance $(\mathrm{CV})$ for standard curve ranged from $1.0 \%$ to $2.3 \%$, and the squared correlation coefficient was 0.9968 .

\section{Statistical Analysis}

Statistical significance of all the data generated was tested by employing ANOVA followed by studentized range test. A confidence limit of $P<.05$ was fixed for interpretation of the results using the software PRISM (GraphPad, Version 2.01, San Diego, CA).

\section{RESULTS AND DISCUSSION}

\section{Characterization of Ethosomal Formulation}

The composition of different ethosomal formulations is summarized in Table 1. TEM photomicrograph of ethosomes revealed the presence of spherical vesicular structures. The entrapment efficiency for lamivudine in optimized ethosomal and liposomal formulation was $57.2 \% \pm 2.5 \%$ and $41.4 \% \pm 1.7 \%$, respectively. The higher entrapment efficiency of lamivudine in ethosomes in comparison to liposomal formulation was probably due to the presence of ethanol in vesicle membrane. ${ }^{17}$ Increasing the concentration of ethanol from $15 \%$ to $45 \%$ increased the entrapment efficiency owing to increase in fluidity of membranes. However, further increase in the ethanol concentration $(>45 \%)$ probably made the vesicle membrane more leaky, thus leading to decrease in entrapment of lamivudine (Table 2).

The size distribution of ethosomes ranged between tens of nanometers to microns and is known to be influenced by the composition of ethosomes. ${ }^{8}$ Table 2 shows that the size of the vesicles decreased when the ethanol concentration was increased from $15 \%$ to $60 \%$. The largest vesicles of $207 \pm$ $19 \mathrm{~nm}$ size were present in the preparation containing $15 \%$ ethanol, while the smallest vesicles of $72 \pm 11 \mathrm{~nm}$ size were present in the preparation containing $60 \%$ ethanol. This significant difference in the size of ethosomal formulations is because of the presence of different concentrations of ethanol. Probably, ethanol causes a modification in net charge of the system and confers it some degree of stearic stabilization that may lead to decrease in mean vesicle size. ${ }^{18}$ Zeta potential measurement study supported by the above hypothesis as zeta potential was observed to be $-2.0 \pm 0.1$ and $-9.5 \pm 2.8$, respectively, for ethosomal formulation containing $15 \%$ and $60 \%$ ethanol.

Table 2. In Vitro Characterizations of Ethosomal Formulations

\begin{tabular}{lcccc}
\hline Formulation Code & Vesicle Size $(\mathrm{nm})$ & Zeta Potential $(\zeta \mathrm{mv})$ & Elasticity & \% Entrapment Efficiency \\
\hline $\mathrm{ETH}_{1}$ & $207 \pm 19$ & $-2.0 \pm 0.1$ & $20.3 \pm 2.2$ & $50.3 \pm 2.6$ \\
$\mathrm{ETH}_{2}$ & $160 \pm 15$ & $-4.8 \pm 0.5$ & $29.2 \pm 2.8$ & $55.7 \pm 2.8$ \\
$\mathrm{ETH}_{3}$ & $102 \pm 13$ & $-8.2 \pm 1.5$ & $38.6 \pm 2.7$ & $57.2 \pm 4.1$ \\
$\mathrm{ETH}_{4}$ & $72 \pm 11$ & $-9.5 \pm 2.8$ & $10.3 \pm 2.7$ & $19.5 \pm 2.0$ \\
$\mathrm{ETH}_{3}-\mathrm{Ch}$ & $152 \pm 12$ & $-5.1 \pm 1.3$ & $16.5 \pm 1.2$ & $57.0 \pm 3.2$ \\
LP & $388 \pm 14$ & $-1.2 \pm 0.6$ & $4.96 \pm 0.8$ & $41.4 \pm 1.7$ \\
\hline
\end{tabular}

All values represent mean \pm SD $(n=3)$ 
AAPS PharmSciTech 2007; 8 (4) Article 111 (http://www.aapspharmscitech.org).

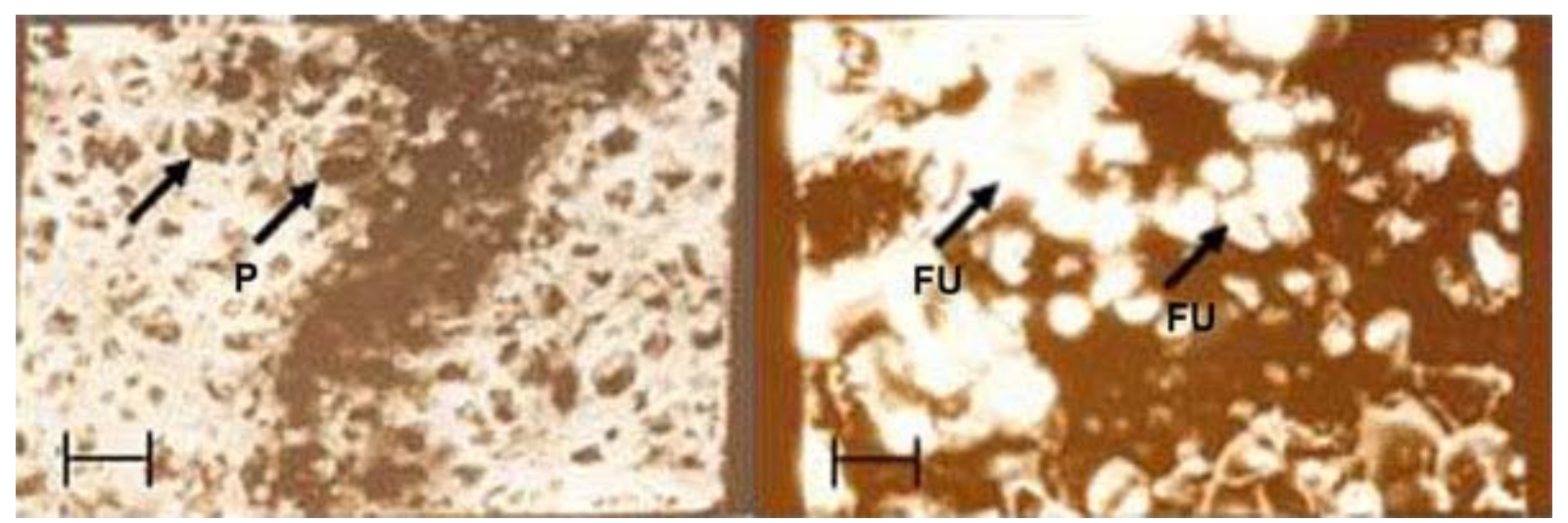

Figure 1. Scanning electron microscope photomicrograph of membrane surface treated with (A) ethosomal and (B) conventional liposomal formulation. $\mathrm{P}$, filter membrane pore; FU, fusion of vesicles on membrane surface. Scale bar $=100 \mathrm{~nm}$. Original magnification $\times 80000$.

\section{Elasticity Measurement}

The elasticity of ethosomal vesicle membrane $(38.6 \pm 2.7)$ was found to be 7-fold higher than liposomes $(4.96 \pm 0.8)$. Higher concentration of ethanol present in ethosomes perhaps provided elasticity to vesicle membrane by reducing the interfacial tension of the vesicle membrane. ${ }^{19}$ In contrast, liposomal formulation contained cholesterol that is known to contribute to rigidity of vesicle membrane. ${ }^{9}$ Inclusion of cholesterol in ethosomal formulation also significantly $(P<.05)$ decreased the elasticity of vesicle membrane (Table 2). The fluidizing effect of ethanol on ethosomal vesicle membrane has been already confirmed by differential scanning calorimetry and fluorescent anisotropy studies. ${ }^{8}$
The SEM photomicrograph of surface of filter membrane treated for 2 hours with ethosomes revealed the absence of residual vesicle material on the filter membrane (Figure 1A). This finding indicated that the vesicle penetrated the 50-nm pores and filled up cavities inside the filter. However, after treatment with conventional liposomes, a large amount of vesicle material was retained on the filter surface (Figure 1B). Liposomes penetrated into the $50-\mathrm{nm}$ pores only to a small extent and appeared to have fused to large multilamellar structures within the filter pores. These observations could be ascribed to the difference in elasticity of these vesicles. Hence, results indicate that ethosomes possess a flexible membrane and can penetrate pores much smaller than their diameter.

Table 3. Skin Permeation Parameters of Lamivudine Calculated From In Vitro Skin Permeation Study Through a Rat Skin (after 24 hours)*

\begin{tabular}{|c|c|c|c|c|c|}
\hline $\begin{array}{l}\text { Formulation } \\
\text { Code }\end{array}$ & $\begin{array}{c}\text { Jss } \dagger \\
\left(\mu \mathrm{g} / \mathrm{cm}^{2} / \mathrm{h}\right)\end{array}$ & $\begin{array}{c}\text { LT }+ \\
\text { (hours) }\end{array}$ & $\begin{array}{c}\mathrm{P} \S \\
(\mathrm{cm} / \mathrm{h}) \times 10^{-3}\end{array}$ & $\begin{array}{c}\mathrm{D} \| \\
\left(\mathrm{Cm}^{2} / \mathrm{h}\right) \times 10^{-3}\end{array}$ & ER \\
\hline $\mathrm{ETH}_{1}$ & $24.8 \pm 2.4$ & 5.8 & 1.1 & 3.2 & 8.9 \\
\hline $\mathrm{ETH}_{2}$ & $58.5 \pm 2.7$ & 4.2 & 2.8 & 6.1 & 20.9 \\
\hline $\mathrm{ETH}_{3}$ & $68.4 \pm 3.5$ & 3.1 & 4.3 & 8.0 & 24.4 \\
\hline $\mathrm{ETH}_{4}$ & $12.5 \pm 1.5$ & 7.6 & 0.8 & 3.5 & 4.5 \\
\hline $\mathrm{ETH}_{3}-\mathrm{Ch}$ & $59.1 \pm 4.5$ & 4.3 & 2.9 & 6.2 & 21.1 \\
\hline LP & $12.6 \pm 0.7$ & 7.5 & 0.8 & 3.5 & 4.5 \\
\hline $2 \% \mathrm{PC}$ in ethanol & $9.1 \pm 1.1$ & 7.9 & 0.6 & 3.3 & 3.3 \\
\hline Ethanolic solution & $6.5 \pm 0.5$ & 8.3 & 0.5 & 3.2 & 2.3 \\
\hline $45 \%$ Ethanol in water & $5.0 \pm 0.6$ & 8.6 & 0.3 & 3.1 & 1.8 \\
\hline Drug solution in PBS (pH 7.4) & $2.8 \pm 0.2$ & 9.4 & 0.1 & 2.8 & - \\
\hline
\end{tabular}

All values represent mean $\pm \mathrm{SD}(\mathrm{n}=3)$

*Jss indicates steady state transdermal flux; LT, logtime; P, permeability coefficient; D, diffusion coefficient; ER, enhancement ratio; LP, liposomes; PC, phosphatidyl choline; and PBS, phosphate buffer saline solution. All values represented as mean \pm standard deviation $(\mathrm{n}=3$ ).

$\uparrow$ Steady-state transdermal flux

tLag time

$\S$ Permeability coefficient

||Diffusion coefficient

IEnhancement ratio 
AAPS PharmSciTech 2007; 8 (4) Article 111 (http://www.aapspharmscitech.org).

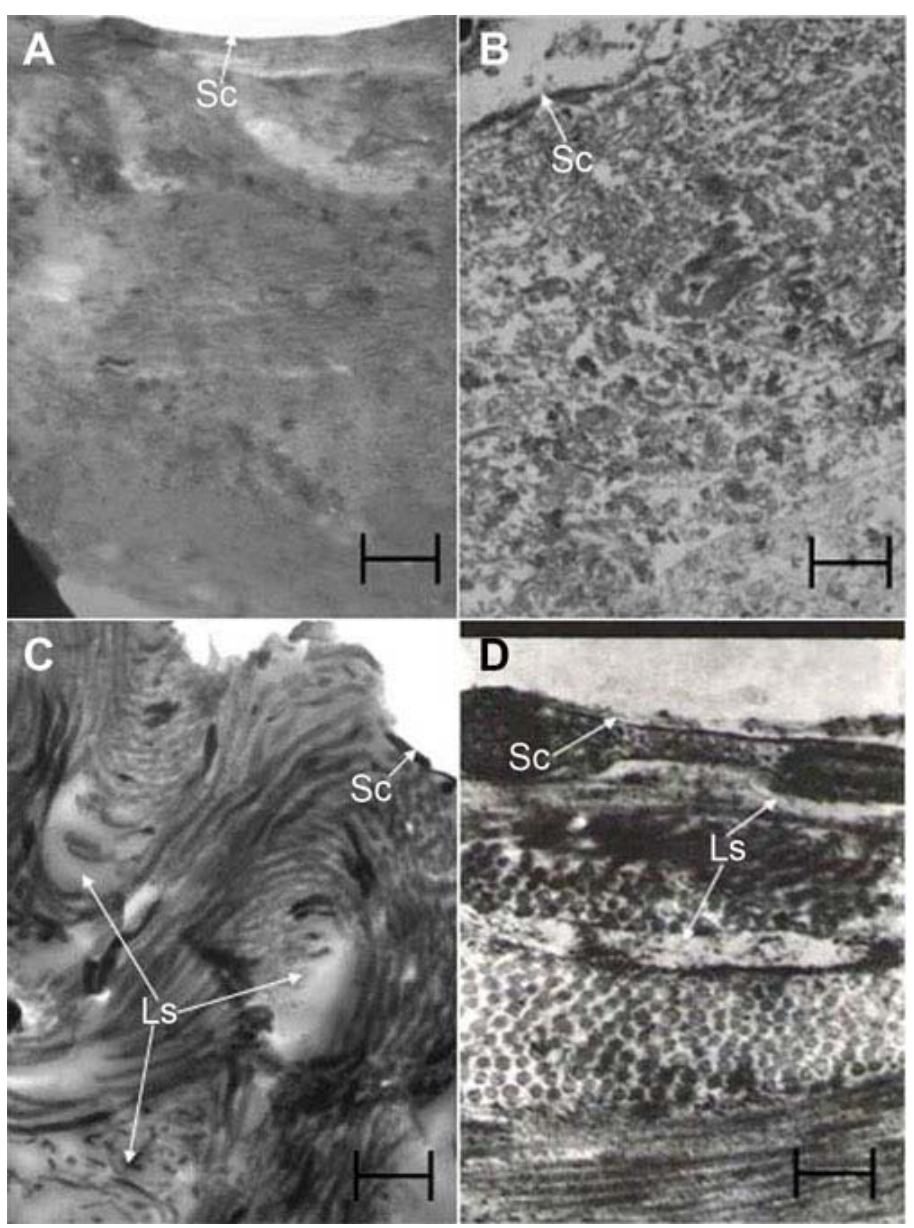

Figure 2. Transmission electron microscope photomicrograph of rat skin treated with (A) phosphate buffer solution, (B) $45 \%$ hydroethanolic solution, (C) ethosomes, and (D) liposomes. Sc, stratum corneum; Ls, lamellar stacks. Scale bar $=100 \mathrm{~nm}$. Original magnification $\times 20000$.

\section{Skin Permeation Studies}

Transdermal flux for different ethosomal formulations across excised rat skin ranged between $24.8 \pm 2.4$ and $68.4 \pm 3.5 \mathrm{ug} /$ $\mathrm{cm}^{2} / \mathrm{h}$ (Table 3). The flux from ethosomes was 8 -fold higher than that obtained after application of $2 \%$ phospholipid solution in ethanol $\left(9.1 \pm 1.1 \mathrm{ug} / \mathrm{cm}^{2} / \mathrm{h}\right), 12$-fold higher than that of the ethanolic solution of drug $\left(6.5 \pm 0.5 \mathrm{ug} / \mathrm{cm}^{2} /\right.$ h), 15-fold higher than that of the $45 \%$ hydroalcoholic solution of drug $\left(5.0 \pm 0.6 \mathrm{ug} / \mathrm{cm}^{2} / \mathrm{h}\right), 5$-fold higher than liposomal formulation $\left(12.6 \pm 0.7 \mathrm{ug} / \mathrm{cm}^{2} / \mathrm{h}\right)$ and 25 -fold higher than the drug solution in PBS $\left(2.8 \pm 0.2 \mathrm{ug} / \mathrm{cm}^{2} / \mathrm{h}\right)$. The data indicated that the transdermal flux of lamivudine increased with increase in the concentration of ethanol in the formulation. However, further increase ( $>45 \% \mathrm{vol} / \mathrm{vol})$ in the ethanol concentration resulted in significant reduction in the transdermal flux of lamivudine. This result could be because of the deteriorating effect on the lipid bilayers when ethanol was present in high concentration. The significantly lower vesicle size $(102 \pm 13 \mathrm{~nm})$ and higher membrane elasticity $(38.6 \pm 2.7)$ of $\mathrm{ETH}_{3}$ formulation is in consonance with the observed highest transdermal flux of drug. Further, significantly higher $(P<.05)$ transdermal flux of lamivudine from ethosomal formulation as compared with that from ethanolic solution clearly indicated that the ethosomal system was more effective in delivering lamivudine than ethanol alone, aqueous ethanolic solution, phospholipid solution, or liposomes. Furthermore, better permeation of lamivudine from ethosomes than from ethanol alone suggested some kind of synergistic mechanism between ethanol, vesicles, and skin lipids (Table 3).

\section{Vesicle Skin Interaction Study}

Touitou et $\mathrm{al}^{8}$ ascribed better permeation of ethosomes to the presence of a high concentration of ethanol that disturbed the skin lipid bilayer organization. However, the exact mechanism by which ethosomes disrupted the skin lipid bilayer organization is still not conclusively established. This information is essential for designing and formulating ethosomes for achieving maximum drug permeation. In the present study, TEM, SEM, and fluorescence microscopy of rat skin treated with ethosomal formulation were performed to determine the effect on histology of skin.

Figure 2A, B, C, and D depict the TEM photomicrographs of rat skin treated with (PBS 6.5), 45\% hydroethanolic solution, optimized ethosomes $\left(\mathrm{ETH}_{3}\right)$, or conventional liposomes, respectively. Formulation $\mathrm{ETH}_{3}$ that was selected for ex vivo and in vivo studies was optimized on the basis of in vitro studies. $\mathrm{ETH}_{3}$ showed maximum entrapment efficiency $(57.2 \% \pm 4.1 \%)$, elasticity $(38.6 \pm 2.7)$, and transdermal flux $\left(68.4 \pm 3.5 \mathrm{ug} / \mathrm{cm}^{2} / \mathrm{h}\right)$. The partial disappearance of lipid lamellae in the upper skin layers indicated that a part of the lipids was extracted by ethanol liberated from ethosomes.

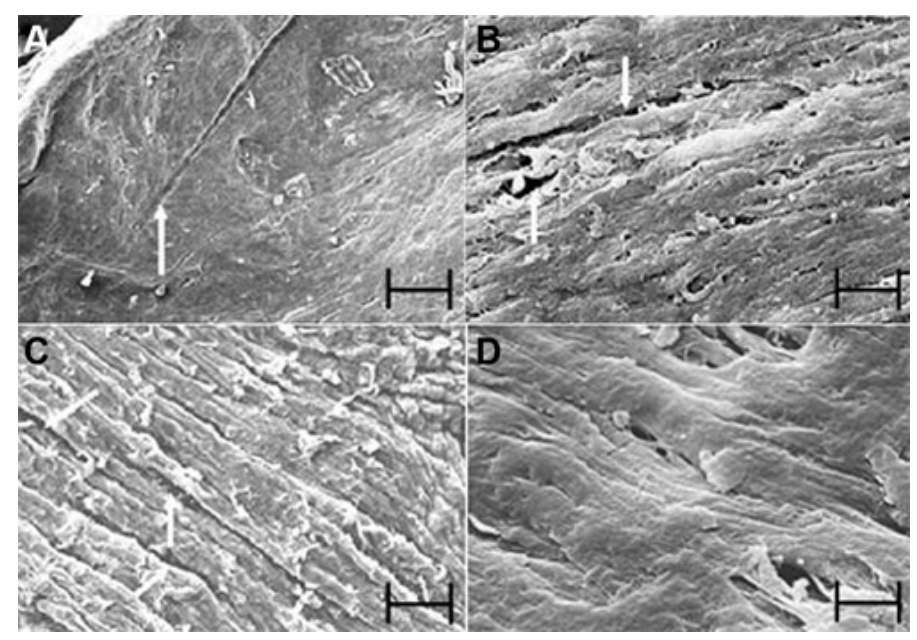

Figure 3. Scanning electron microscope photomicrograph of rat skin treated with (A) phosphate buffer solution, (B) 45\% hydroethanolic solution, (C) ethosomes, and (D) and liposomes. Scale bar $=100 \mathrm{~nm}$. Original magnification $\times 15000$. 
AAPS PharmSciTech 2007; 8 (4) Article 111 (http://www.aapspharmscitech.org).

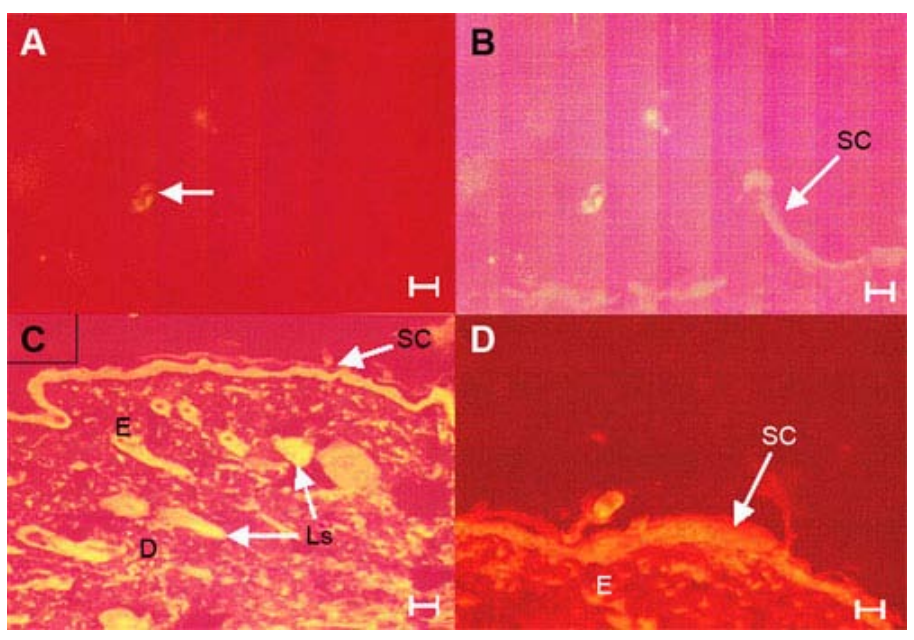

Figure 4. Depositions of fluorescence probe Rhodamine 123 into rat skin after application as (A) solution, (B) 45\% hydroethanolic solution, (C) ethosomes, and (D) liposomes. SC, stratum corneum; E, epidermis; D, dermis; Ls, lamellar stacks. Scale bar $=500 \mu \mathrm{m}$. Original magnification $\times 450$.

Areas of lipids with electron dense material and lamellar stacks that are known to be fixed by osmium tetraoxide $\left(\mathrm{OsO}_{4}\right)$ were visualized deeper down in the stratum corneum (Figure 2C). Because SC lipid lamellae cannot be fixed by $\mathrm{OsO}_{4},{ }^{20}$ it is hypothesized that the observed stained material originated from the vesicles. The lamella stacks appeared squeezed in between the bilayers of the intercellular spaces, thereby disrupting the highly organized Landmann units and creating dislocation. This can be attributed to the deformable nature of ethosomes. These $\mathrm{OsO}_{4}$ fixed lipid areas, containing electron dense material, were not observed in PBS and liposome-treated rat skin (Figure 2A and D). Further, no ultrastructural changes were observed in skin layers indicating that rigid liposomal formulation did not induce any ultrastructural changes in the SC and accumulated only in the top layer of the skin. In contrast, skin treated with hydroalcoholic solution showed partial extraction of skin lipids and did not cause any effect on the ultrastructure of skin. The magnitude of extraction of lipid by liposomes appeared to be significantly less than the ethosomal formulation. These results correlated well with the mechanism of percutaneous absorption of ethanol that is reported to cause partial lipid extraction. ${ }^{21}$ These results illustrated that ethosomes might act not only in superficial SC layers but may also induce lipid perturbations in deeper layers of the SC (evidenced by presence of lamellar stacks in deeper layer of skin), while gel state vesicles interacted only with the outermost layers in the SC. In addition, fusion of conventional liposomal vesicles on top of the SC might also act as an additional barrier for diffusion of drugs, which would eventually restrict permeation of drug across skin.

Figure 3A, B, C, and D show the SEM photomicrograph of rat skin treated with PBS (control), 45\% hydroethanolic solution, ethosomal formulation $\left(\mathrm{ETH}_{3}\right)$, and liposomal formulation, respectively. In comparison to control skin, ethosome-treated skin appeared rough, and some vesicular structures were present on the surface (Figure 3C). The morphology of the cell was changed, and some partial disappearance of intercellular lipid was observed (indicated by arrow). The increase in the intralamellar distance of SC lipids was also observed. The results of SEM and TEM studies together support the hypothesis that the synergistic effect of the combination of ethanol and phospholipid in ethosomes is responsible for its better skin permeability. Ethanol is reported to provide a pathway of diminished resistance for drug transport because of the partial extraction of SC lipids. ${ }^{22}$ Therefore, when ethosomal formulation was applied on skin, released ethanol from ethosomes increased the fluidity of intercellular lipid bilayer of SC and caused its partial extraction. This increase in fluidity of the intercellular bilayer by ethanol seems to permit easier vesicle diffusion through the SC.

Fluorescence photomicrograph of the skin after 6-hour application of fluorescence marker Rhodamine 123 as solution (control), 45\% hydroethanolic solution, loaded-ethosomal, and liposomal formulation are shown in Figure 4A, B, C, and $\mathrm{D}$, respectively. Penetration from conventional liposomes was limited to upper layer of skin (SC). Deep penetration (viable epidermis and dermis) from alcohol-free liposomes was almost negligible (Figure 4D). In contrast, enhanced delivery of Rhodamine 123 in terms of depth (viable epidermis, dermis, and adipose tissue) and intensity (dermis layer) was observed when loaded in ethosomes. Further, the presence of fluorescence in the interlipoidal pathway indicated that ethosomes followed this pathway for skin penetration. Forty-five percent hydroethanolic solution of Rhodamine 123 (Figure 4B) showed very weak fluorescence in comparison to ethosomal formulation (Figure 4C).

Table 4. Stability Study of Optimized Ethosomal Formulation $\left(\mathrm{ETH}_{3}\right)$ and Liposome

\begin{tabular}{lcccc}
\hline & \multicolumn{2}{c}{ Initial } & \multicolumn{2}{c}{ After 180 days } \\
\cline { 2 - 5 } Parameters & Ethosomes & Liposomes & Ethosomes & $98 \pm 12$ \\
\hline Vesicle size & $102 \pm 13$ & $388 \pm 14$ & $412 \pm 28$ \\
Zeta potential & $-8.2 \pm 1.5$ & $-1.2 \pm 0.6$ & $-8.0 \pm 1.3$ & $55.4 \pm 3.9$ \\
Entrapment efficiency & $57.2 \pm 4.1$ & $41.4 \pm 1.7$ & $36.3 \pm 2.9$ \\
\hline
\end{tabular}




\section{Stability Study}

Table 4 summarized the data of the stability study of optimized ethosomal and liposomal formulation. Data indicate that there was no significant change in vesicle size, zeta potential, and the entrapment efficiency value of ethosomal formulation. This finding indicated good storage stability of ethosomal formulation. These results are in agreement with literature reports ${ }^{4,11}$ indicating that ethosomes possess reasonably good stability in comparison to liposomes because of the presence of ethanol. Ethanol provides a net negative surface charge, which avoids aggregation of vesicles due to electrostatic repulsion.

\section{Cell Line Study}

The cytotoxicity of vesicular formulation was determined by MTT assay and the results are summarized in Figure 5. No significant toxicity was observed up to the concentration of $0.58 \mu \mathrm{mol} / \mathrm{mL}$ of lamivudine in ethosomal and liposomal formulations. In contrast, in case of marked oral solution formulation and drug solution in PBS, cytotoxic concentration was observed at $0.24 \mu \mathrm{mol} / \mathrm{mL}$ concentration. The results of the cytotoxicity assay showed that encapsulation in vesicular formulations decreased the cytotoxicity of lamivudine. Therefore, in order to avoid any cytotoxic effects of formulations, cellular uptake studies were conducted using $0.58 \mu \mathrm{mol} / \mathrm{mL}$ of lamivudine.

Figure 6 shows that the cellular uptake of lamivudine from ethosomal formulation was significantly $(P<.05)$ higher than drug solution $(85.7 \% \pm 4.5 \%$ and $24.9 \% \pm 1.9 \%$ for ethosomes and drug solution, respectively) after 3 hours of incubation. Encapsulation of lamivudine in vesicular formulation resulted in a higher drug accumulation in MT-2 cell lines as compared with drug solution. Godin and Touitou ${ }^{23}$ also recently reported better cellular uptake of bacitracin in

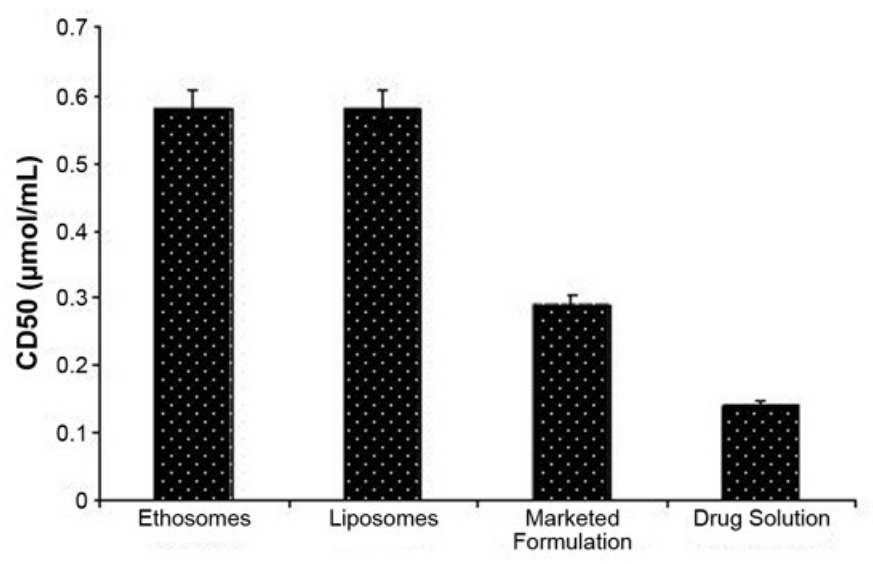

Figure 5. Cytotoxic dose $\left(\mathrm{CD}_{50}\right)$ of lamivudine after administration in ethosomes $\left(\mathrm{ETH}_{3}\right)$, liposomes, marketed formulation, and drug solution. All values shown as mean $\pm \mathrm{SD}(\mathrm{n}=3)$.

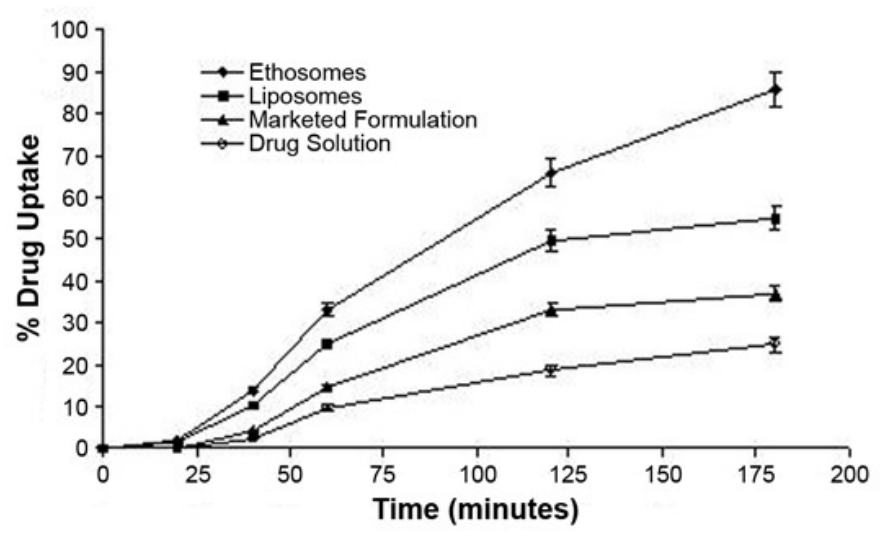

Figure 6. Comparative cellular uptake of lamivudine after administration with ethosomes $\left(\mathrm{ETH}_{3}\right)$, liposomes, marketed formulation, and drug solution in MT2 cells. All values shown as mean \pm standard deviation $(n=3)$.

3T3 dermal fibroblast cells from ethosomes. The results of these studies showed better intracellular drug delivery from ethosomes. Better intracellular uptake of drugs from ethosomal formulation was ascribed to preferential uptake of vesicles by phagocytic cells. ${ }^{24}$ Phagocytic cells of Reticuloendothelial system (RES) preferentially take up vesicular formulations in vivo because of the presence of scavenger receptor expressed on macrophages. ${ }^{25}$ Vesicular entrapment of lamivudine may be valuable for its targeted delivery because vesicular formulation accumulates in the reticuloendothelial tissues, where HIV resides and replicates. ${ }^{24}$

\section{CONCLUSION}

The results of the visualization study indicate that ethosomal formulation affected the normal histology of skin by producing lipid perturbation and increasing the intercellular lipid lamellae space of the SC. Lipid perturbation, along with elasticity of ethosomes vesicles, seems to be the main contributor for its improved skin permeation.

\section{ACKNOWLEDGMENTS}

The authors are grateful to Council for Scientific and Industrial Research (CSIR), New Delhi, India, for financial assistance (grant number 9/150(79)/2k2/EMR-I) and to the Director, Electron Microscopy Section, AIIMS, New Delhi, India, for providing the facilities for transmission and scanning electron microscopy study.

\section{REFERENCES}

1. Jarvis B, Faulds D. Lamivudine: a review of its therapeutic potential in chronic hepatitis B. Drugs. 1999;58:101-141.

2. Dutta T, Jain NK. Targeting potential and anti-HIV activity of lamivudine-loaded mannosylated poly(propyleneimine) dendrimer. Biochim Biophys Acta. 2007;1770:681-686. 


\section{AAPS PharmSciTech 2007; 8 (4) Article 111 (http://www.aapspharmscitech.org).}

3. Schreier H, Bouwstra J. Liposomes and niosomes as a drug carriers: dermal and transdermal drug delivery. J Control Release. 1994;30:1-15.

4. Cevc G, Blume G, Schatzlein A, Gebauer D, Paul A. The skin: a pathway for the systemic treatment with patches and lipid based agent carriers. Adv Drug Deliv Rev. 1996;18:349-378.

5. Touitou E, Dayan N, Bergelson L, Godin B, Eliaz M. Ethosomes novel vesicular carriers for enhanced delivery: characterization and skin penetration properties. J Control Release. 2000;65:403-418.

6. Touitou E, inventor. Composition of applying active substance to or through the skin. US patent 5540 934. July 30, 1996.

7. Touitou E, inventor. Composition of applying active substance to or through the skin. US patent 5716 638. October 2, 1998.

8. Touitou E, Godin B, Dayan N, Weiss C, Piliponsky A, Levi-Schaffer F. Intracellular delivery mediated by an ethosomal carrier. Biomaterials. 2001;22:3053-3059.

9. Jain S, Umamaheshwari RB, Bhadra D, Jain NK. Ethosomes: a novel vesicular carrier for enhanced transdermal delivery of an anti-HIV agent. Ind J Pharma Sci. 2004;66:72-81.

10. Bangham AD, Standish MM, Watkins JC. The action of steroids and streptolysin $\mathrm{S}$ on the permeability of phospholipid structures to cations. J Mol Biol. 1965;13:253-259.

11. Lopez-Pinto JM, Gonzalez-Rodriguez ML, Robasco AM. Effect of cholesterol and ethanol on dermal delivery of DPPC liposome. Int $J$ Pharm. 2005;298:1-12.

12. Jain S, Jain P, Jain NK. Transfersomes: a novel vesicular carrier for enhanced transdermal delivery: development, characterization and performance evaluation. Drug Dev Ind Pharm. 2003;29:1013-1026.

13. Jain S, Jain N, Bhadra D, Tiwary AK, Jain NK. Transdermal delivery of an analgesic agent using elastic liposomes: preparation, characterization and performance evaluation. Curr Drug Deliv. 2005;2:223-233.

14. Bedoya LM, Sanchez-Palomino S, Abad MJ, Bermejo P, Alcami J. Anti-HIV activity of medicinal plant extracts. $J$ Ethnopharmacol. 2001;77:113-116.

15. Dusserre N, Lessard C, Paquette N, et al. Encapsulation of foscarnet in liposomes modifies drug intracellular accumulation, in vitro anti-HIV-1 activity, tissue distribution and pharmacokinetics. AIDS. 1995;9: 833-841.

16. Uslu B, Ozkan SA. Determination of lamivudine and zidovudine in binary mixtures using first derivative spectrophotometric, first derivative of the ratio-spectra and high performance liquid chromatography-UV methods. Anal Chim Acta. 2002;466:175-185.

17. Paolino D, Lucania G, Mardente D, Alhaique F, Fresta M. Ethosomes for skin delivery of ammonium glycyrrhizinate: in vitro percutaneous permeation through human skin and in vivo anti-inflammatory activity on human volunteers. J Control Release. 2005;106:99-110.

18. Lasic D, Weiner N, Riaz M, Martin F. Liposomes. In: Lieberman A, Rieger M, Banker G, eds. Pharmaceutical Dosage Forms: Disperse Systems. vol. 3. New York, NY: Marcel Dekker; 1998;43-86.

19. Dayan N, Touitou E. Carriers for skin delivery of trihexyphenidyl HCl: ethosomes Vs liposomes. Biomaterials. 2000;21:1879-1885.

20. Van den Bergh BAI, Swartzendruber DC, Bos-Van der Geest A, et al. Development of an optimal protocol for the ultrastructural examination of skin by transmission electron microscopy. J Microscopy. 1997;187: 125-133.

21. Kim YH, Ghanem AH, Mahmoud H, Higuchi WI. Short chain alkanols as transport enhancers for lipophilic and polar/ionic permeants in hairless mouse skin: mechanism(s) of action. Int $J$ Pharm. 1992;80:17-31.

22. Krishnaiah YSR, Bhaskar P, Satyanarayana V. Penetration-enhancing effect of ethanol water solvent system and ethanolic solution of carvone on transdermal permeability of nimodipine from HPMC gel across rat abdominal skin. Pharm Dev Technol. 2004;9:63-74.

23. Godin B, Touitou E. Mechanism of bacitracin permeation enhancement through the skin and cellular membrane from an ethosomal carrier. $J$ Control Release. 2004;187:1-15.

24. Oussoren C, Magnani M, Fraternale A, et al. Liposomes as carrier of the antiviral agent dideoxycytidine-5'-triphosphate. Int J Pharm. 1999; 180:261-270.

25. Brown MS, Goldstein JL. Lipoprotein metabolism in the macrophage: implication for cholesterol deposition in atherosclerosis. Annu Rev Biochem. 1983;52:223-261. 